ECOLOGY AND SOCIETY

Home | Archives | About | Login | Submissions | Notify | Contact | Search

\author{
ES HOME > VOL. 5, NO. 2 > ART. 5
}

Copyright (c) 2001 by the author(s). Published here under license by The Resilience Alliance.

The following is the established format for referencing this article:

Tyson, W. 2001. Fuzzy philosophy: a foundation for Interneted ecology? Conservation Ecology 5(2): 5. [online]

URL: http://www.consecol.org/vol5/iss2/art5/

\title{
Insight
}

\section{Fuzzy Philosophy: A Foundation for Interneted Ecology?}

\author{
Wayne Tyson
}

- $\underline{\text { Responses to this Article }}$

Published: November 7, 2001

We are inundated with facts, daunted by data, overwhelmed with complicatedness; our senses are more overloaded than ever before. My use of the word "complicatedness" is intentional. It is my intention to draw a distinction between what is complicated and what is complex, between fuzzy and fussy.

One predawn in the mid-1960s, Lofti Zadeh experienced an "Ah-HA!" phenomenon: the birth of an idea that had been gestating for a long time in his subconscious. It was a synthesis of mathematics and common sense that he called "fuzzy logic." This was an unfortunate choice of name, perhaps, but an honest one and, ironically, a precise one. However, that was precisely the problem. Little did Zadeh realize (or perhaps he realized it profoundly) that his departure from the rut of literal precision would put him in grave danger, at least in a figurative sense. It figures. Innovators are burned at the stake, and Lofti was no exception. The major U.S. "think" corporation tossed him out, figuratively, on his ear. Companies in Japan, however, embraced him and his ideas and ran with them. Fuzzy machines in Japan run smoothly; others jerk at their jobs.

Ecology is fuzzy. It does not fit into the literal pigeonholes of conventional science. Any attempt to hammer it into neat, number-bound categories produces a complicated snarl of data that almost no one can be bothered to unravel (for "unravel," read "critically review"). Conventional statistics confound more than they reveal about complex interactions. Attempting to deal with too many variables has undone countless quixotic researchers trying to balance on the high wire between academic acceptance and intuition, which, as we all know, is a bugbear to be avoided at all costs.

"Fuzzy thinking" (FT) is not precise. It reflects truths, not mere facts or statistics without meaning. It represents the degree to which something is factual. It makes no unsupportable, or worse, irrelevant claims, such as decimal points that imply more accuracy than they can deliver. FT welcomes change. It is an analytical procedure in motion. Because it does not produce ragged data points, there is no need to smoothe out the curves. It is more complex than simple counting, but not more complicated. It is not difficult. It requires, however, a different mindset than that of conventional analysis-by-count.

FT first asks if a particular conclusion, which is always tentative, is more true than untrue, or more untrue than true. By progressive steps, it backs and fills its way, merely reflecting the observed phenomena (and, unfortunately, the ability of the observer to maintain his or her integrity in the face of conventional assumptions). There are no conclusions in the sense of static finality, but rather a sliding scale-perhaps even a jiggling scale-no, a nonscale. This produces a four-dimensional (Might there be a fifth? A sixth?) view of the jiggling, scaleless, squishy, fuzzy phenomena we label ecological processes. Is a good rough guess better than a precise poor one? Is a rough guess more relevant or less relevant than a precise one? What are the uses of imprecision? We do not know the numerical (scale) values for the letters and symbols on a keyboard. This is not "intuition" in the popular sense, but it is the "fuzzy" part of the brain at work. And the work it does is arguably on a far more complex plane than the one that relies on relatively complicated scale coordinates to find keys. Just try thinking about key locations while typing and see what happens. 
To take advantage of this fuzzy philosophy, a great simplification will be necessary. We will have to learn to communicate via connected sequences, probably with symbols. The trend toward acronyms may be the early stages of this evolution. In this regard, the presumptuous West may well find itself eclipsed by the patient East, long accustomed to symbolic communication with connected concepts rather than strings of words constructed from microsymbols (letters of alphabets) that have relatively little meaning in and of themselves. Probably a whole new meta-language will evolve that is simpler, less prone to misunderstanding, and universal. The almost universally despised and ridiculed right brain will have to be used despite the cries of outrage from fans of linear thinking. Complex, multifaceted phenomena can be comprehended only by understanding the nature of their connections and disconnections over time and space. A view of any phenomenon based on its parts alone lacks integrity. The solution is to integrate and connect.

At the moment, the Internet is a model of this traditional fragmentary approach, limping along according to established paradigms and assumptions. Users are at the mercy of toy-trained techies flashing their latest graphics and of corporations deluded enough to think that all they need to connect with their customers is a "presence" cum ad poster. However, the Internet has the potential to promote true connections between individual users, and companies who do not take advantage of this ability will soon be as irrelevant as a buggy whip (save, perhaps, having vector dynamics in common) on a spaceship. It's evolution all over again. Even listserves and on-line journals must change. The ultimate survivors will be the entities that connect most widely, deeply, frequently, and permanently with their relevant congeners. This synergy will produce a highly productive and efficient organism and ecosystem, an Interneted ecology that will serve a wider range of entities "sustainably." Just as in nature, this evolution will happen whether or not dominant wills decide to aid or resist the process. Predators as well as prey must be sorted out in accordance with their relevance to the larger system and with the resulting changes. Predators that consume the breeding stock of their prey populations will die. No Federal Reserve System can change that.

This is not to say that those entities whose wills most closely correspond with reality rather than their images of themselves will not prevail sooner. However, that depends on how well such entities read the fast-changing habitat and recognize the new connections and binding sites and act accordingly. From the subatomic to the universe, the principle holds true that only the true can exist; all else is fantasy. All reality is ecology. To embrace the fuzzy principle is to align with the tides and cues from the streams of our origins, ignoring the schooling multitudes that lead toward greater confinement of mind and destiny.

\section{RESPONSES TO THIS ARTICLE}

Responses to this article are invited. If accepted for publication, your response will be hyperlinked to the article. To submit a comment, follow this link. To read comments already accepted, follow this link.

\section{Address of Correspondent:}

Wayne Tyson

P.O. Box 34069

San Diego, California 92163 USA

Phone: (619) 280-2553

Fax: none

landrest@utm.net 